\title{
DRY SLIDING WEAR BEHAVIOUR OF SAND CAST Cu-11Ni-6Sn ALLOY
}

\author{
S.Ilangovan ${ }^{1}$, S.Jiten ${ }^{2}$ \\ ${ }^{I}$ Assistant Professor (SG), Mechanical Department, Amrita School of Engineering, Amrita Vishwa Vidyapeetham, \\ Coimbatore - 641105, Tamilnadu, India \\ ${ }^{2}$ M.Tech. Student, Mechanical Department, Amrita School of Engineering, Amrita Vishwa Vidyapeetham, \\ Coimbatore - 641105, Tamilnadu, India
}

\begin{abstract}
Wear behaviour of sand cast Cu-11Ni-6Sn alloy was studied using pin-on-disc wear tester with alloy steel disc as counterpart on dry sliding wear conditions. The alloy was prepared from pure elements and melted in an electric furnace under argon atmosphere and cast into sand moulds. The cast rods were homogenized, solution heat treated and aged. Specific wear rate and coefficient of friction were measured in a sliding speed of $191 \mathrm{rpm}, 287 \mathrm{rpm}$ and $382 \mathrm{rpm}$ and different normal forces of $10 \mathrm{~N}, 15$ $N$ and $20 \mathrm{~N}$. Hardness of the specimen was found to increase by the aging process and it reached its maximum value, after which it decreased. The specific wear rate was found to increase with the increase in normal load and it decreased with the increase in speed. Co-efficient of friction is independent of hardness of the alloy and dependent on both applied load and speed. The strength of the material is increased by a technique called spinodal decomposition and aging process. In the case of Cu-Ni-Sn system the various alloy composition was not tested for tribological behaviour. Only few alloy compositions are studied. So in this case we have taken $\mathrm{Cu}-11 \mathrm{Ni}$-6Sn alloy composition. The products made by $\mathrm{Cu}$-Ni-Sn alloy is less costlier compared to Cu-Be products without health hazard and used as high performance connector materials in electronics applications, bearing material in aerospace and mining industries, friction-reducing and anti-wear materials to make high performance bearings for aerospace, roller cone, rock bit and heavy duty mobile industrial equipment.
\end{abstract}

Keywords: Copper-Nickel-Tin alloy, Spinodal decomposition, Modulated Structure, Wear, Aging

\section{INTRODUCTION}

Copper alloys are extensively used as bearing materials against ferrous alloys. They have outstanding sliding wear resistance due to their high tribological compatibility in opposition to ferrous alloys. The high thermal conductivity of the copper alloys can dissipate friction heat; hence they are more appropriate for many engineering applications [1]. It is well recognized that Copper-Beryllium (Cu-Be) alloys are used in high strength applications. The strength of these alloys is obtained through cold work, precipitation hardening and age hardening treatment. But it is harmful and costly [2-3]. In order to address these problems, spinodal Bronze alloys are considered as appropriate substitutes for $\mathrm{Cu}-\mathrm{Be}$ alloys. Spinodal Bronze comprises of the alloy composition of copper-nickel-tin (Cu-Ni-Sn), which attains high strength through solution heat treatment and aging process. During the solution heat treatment process, the alloy decomposes spinodally, forming a modulated microstructure [4-5]. In addition to this, aging process leads to the formation of ordered structures, which provide high strength to $\mathrm{Cu}-\mathrm{Ni}-\mathrm{Sn}$ alloys [6]. Processing the $\mathrm{Cu}-\mathrm{Ni}-\mathrm{Sn}$ alloys with suitable composition, \% cold work, aging temperature and time will provide strength nearly equivalent to $\mathrm{Cu}-\mathrm{Be}$ alloys.

In this study, an alloy of composition $\mathrm{Cu}-11 \mathrm{Ni}-6 \mathrm{Sn}$ was chosen. The effect of aging temperature on hardness and the wear behaviour was studied.

\section{EXPERIMENTAL PROCEDURE}

The raw materials required to prepare the alloy was procured in pure form from the commercial market. The wooden pattern was used to make the alloy rods to the required dimension. Sand mould was prepared with the help of wooden pattern. The appropriate composition and quantity of the raw materials was melted at $1250{ }^{\circ} \mathrm{C}$ under inert Argon atmosphere using electric furnace. The molten metal was poured into sand mould. The cast rods of diameter $0.016 \mathrm{~m}$ and length $0.150 \mathrm{~m}$ were taken out from the mould after solidification. All the cast rods were homogenized, solution heat treated and aged. Homogenization was carried out at $825{ }^{\circ} \mathrm{C}$ for 10 hours. Solution heat treatment was performed at $825^{\circ} \mathrm{C}$ for 1 hour and rapidly quenched in cold water maintained at room temperature. After solution heat treatment, aging was done at $350{ }^{\circ} \mathrm{C}$. During the aging process, at one hour interval one cast rod was withdrawn from the furnace and cooled normally. From these heat treated rods, specimens were prepared to conduct hardness test and wear test.

The hardness of the specimens were tested using Vickers micro-hardness tester (Make: Mitutoyo; Model: HM-210A). The wear properties were studied by using Pin-on-Disc wear tester (Make: Ducom Instruments; Model: TR20). The wear loss was expressed in terms of specific wear rate $\left(\mathrm{mm}^{3} / \mathrm{Nm}\right)$ by finding the volume loss $\left(\mathrm{mm}^{3}\right)$ and then divided by sliding distance $(\mathrm{m})$ and applied load $(\mathrm{N})$. The specimen 
size used was $\varnothing 0.01 \mathrm{~m} \times 0.04 \mathrm{~m}$ length. The wear test was performed at three loads such as $10 \mathrm{~N}, 15 \mathrm{~N}$ and $20 \mathrm{~N}$ and at three speeds $191 \mathrm{rpm}, 287 \mathrm{rpm}$ and $382 \mathrm{rpm}$. The sliding track diameter was $0.09 \mathrm{~m}$ and the specimen sliding duration was 10 minutes.

\section{RESULTS AND DISCUSSIONS}

\subsection{Hardness}

Figure 1 shows the variation of the Vickers hardness of the specimen when it was aged from solution heat treated condition to 5 hours. The plot shows that the hardness increases from $238 \mathrm{HV}$ to $410 \mathrm{HV}$ and then decreases to 389 $\mathrm{HV}$ during the aging process. The maximum hardness was obtained at 4 hours of aging time. Beyond that, it started to decrease. At zero aging time, the specimen was in solution heat treated condition. Spinodal decomposition started to occur at this stage, forming a modulated microstructure. When aging started, in addition to spinodal decomposition, an ordering reaction also took place, which increased the hardness of the alloy. For this alloy composition, the ordering reaction was completed at 4 hours of aging. Further aging resulted in the formation of grain boundary precipitates, which reduced the hardness of the alloy. It was reported that the modulated structure and the ordered structures are not visible through optical microscope. The behaviour of the hardness with aging time was consistent with that of previous reports [3, 7-8]. So it may be concluded that during the aging process, the hardness of the alloy increases, which is due to microstructural changes.

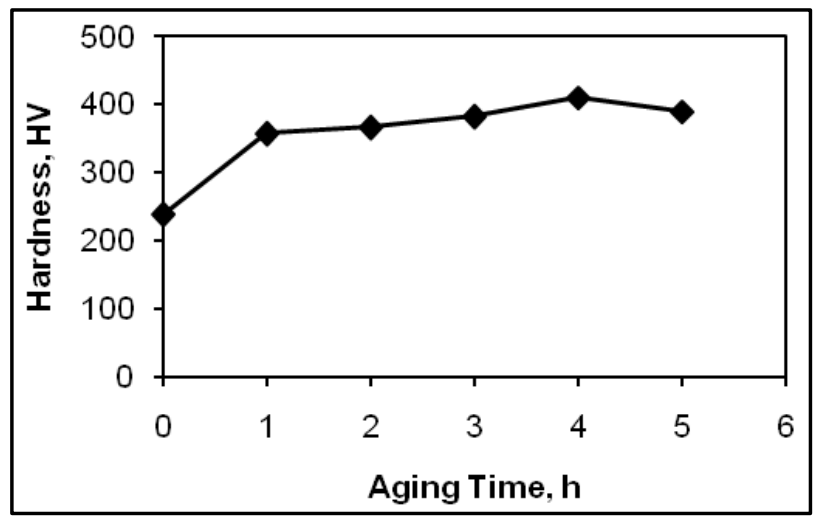

Fig1: Variation of hardness with aging time, aged at $350{ }^{\circ} \mathrm{C}$

\subsection{Specific Wear Rate versus Load}

To find out the specific wear rate, each aged specimen was tested for $10 \mathrm{~N}, 15 \mathrm{~N}$ and $20 \mathrm{~N}$ normal loads while sliding speed was kept constant (191 rpm). From Figure 2, it was observed that the specific wear rate increases as the normal load increases from $10 \mathrm{~N}$ to $20 \mathrm{~N}$. The same behaviour was observed when the sliding speed was changed to $287 \mathrm{rpm}$ and $382 \mathrm{rpm}$ as shown in Figure 3 and Figure 4 respectively. It is due to the fact that, as increase in normal load triggers more frictional heat generation at the contact surface, which results in reduction of the strength of the material [9]. Hence, it may be concluded that the specific wear rate increases when the normal load increases. But this may not be true for all loads. Initially, the specific wear rate increases up to certain loads and then remains constant [10]. This behaviour is due to the strain hardening effect at the contact surface. Further, from the Figure 2, it was found that the specific wear rate varies with aging time. At four hours of aging, the specific wear rate is minimum, which is due to maximum hardness of the alloy at this aging time. Hence, it may also be concluded that the specific wear rate is a function of the hardness of the alloy.

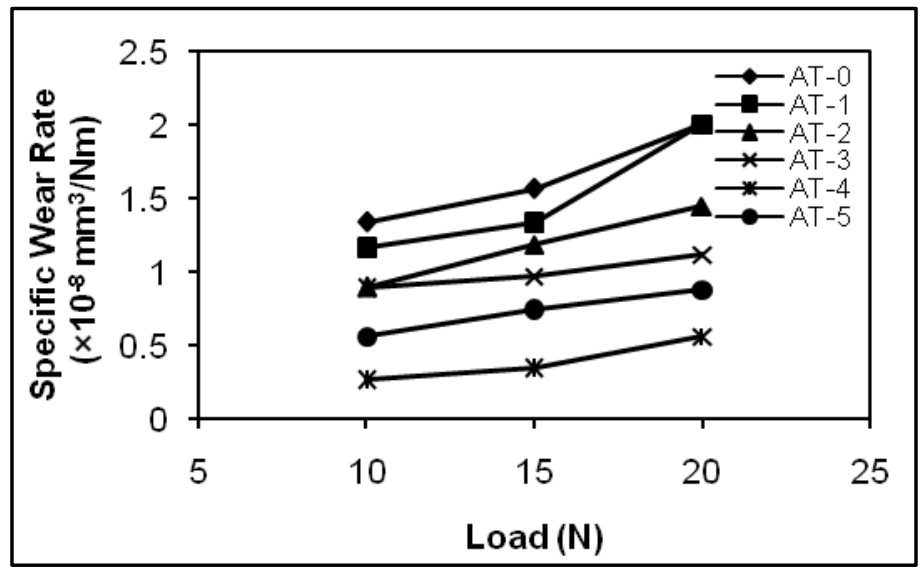

Fig2: Variation of specific wear rate with load for aging time up to 5 hours $($ Speed $=191 \mathrm{rpm})$

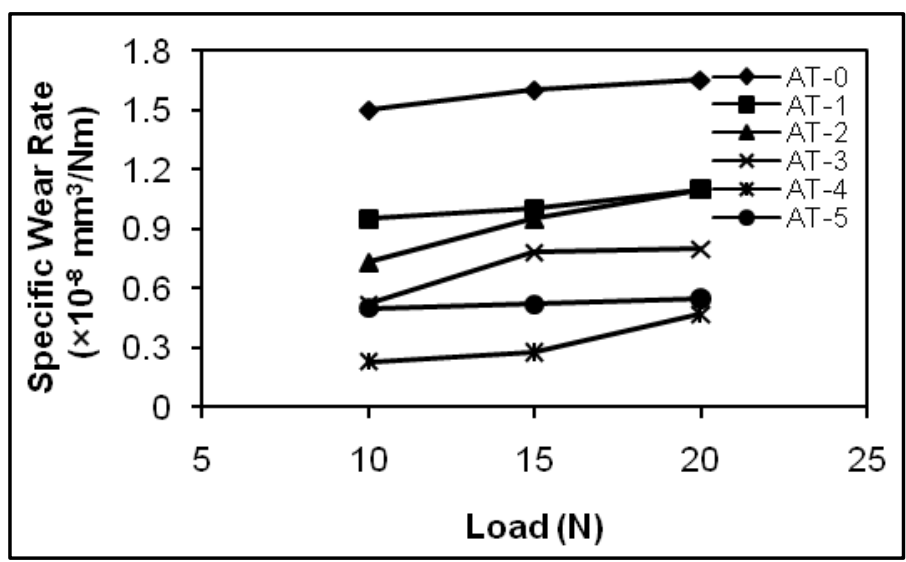

Fig3: Variation of specific wear rate with load for aging time up to 5 hours $($ Speed $=287 \mathrm{rpm})$

Figure 5 shows the specific wear rate of four hours aged specimen as a function of applied load for different sliding velocities. It can be observed that the specific wear rate increases in all cases with the increase of applied load and the decrease of sliding speed. Hence, it may also be concluded that the specific wear rate will be dependent on both the load and the sliding speed. 


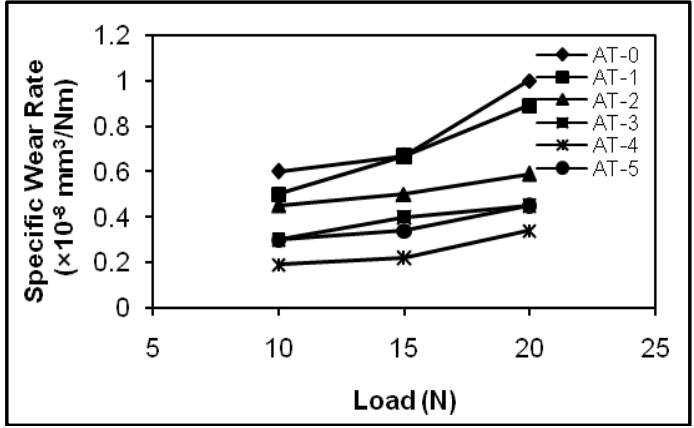

Fig4: Variation of specific wear rate with load for aging time up to 5 hours $($ Speed $=382 \mathrm{rpm})$

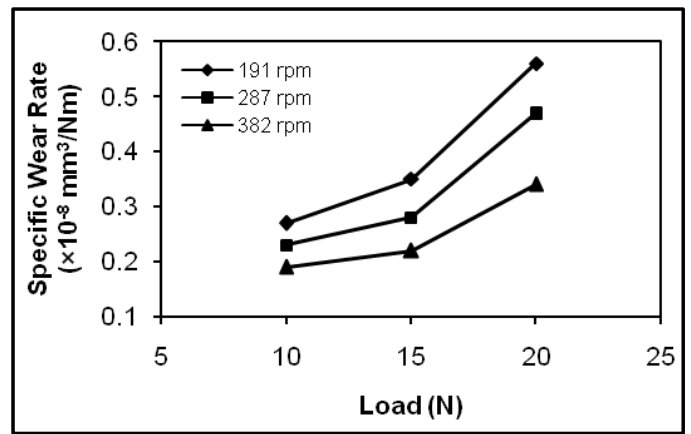

Fig5: Variation of specific wear rate with load and speed

\subsection{Specific Wear Rate versus Speed}

In this case, each aged specimen was tested for $191 \mathrm{rpm}$, $287 \mathrm{rpm}$ and $382 \mathrm{rpm}$ while the load was kept constant (10 N). From Figure 6, it was observed that the specific wear rate decreases as the speed increases from $191 \mathrm{rpm}$ to 382 $\mathrm{rpm}$. This is due to the fact that the duration of sliding (10 minutes) is same for all sliding speeds and hence the length of sliding is more in case of higher speed [9]. The same behaviour was observed when the load was changed to $15 \mathrm{~N}$ and $20 \mathrm{~N}$ as shown in Fig. 7 and Fig. 8 respectively. Hence, it was concluded that the specific wear rate decreases as the speed increases. Further, it was observed that the specific wear rate was least at four hours of aging. It is due to the attainment of maximum hardness of the alloy at this aging time. Hence, specific wear rate is a function of the hardness of the alloy as stated above.

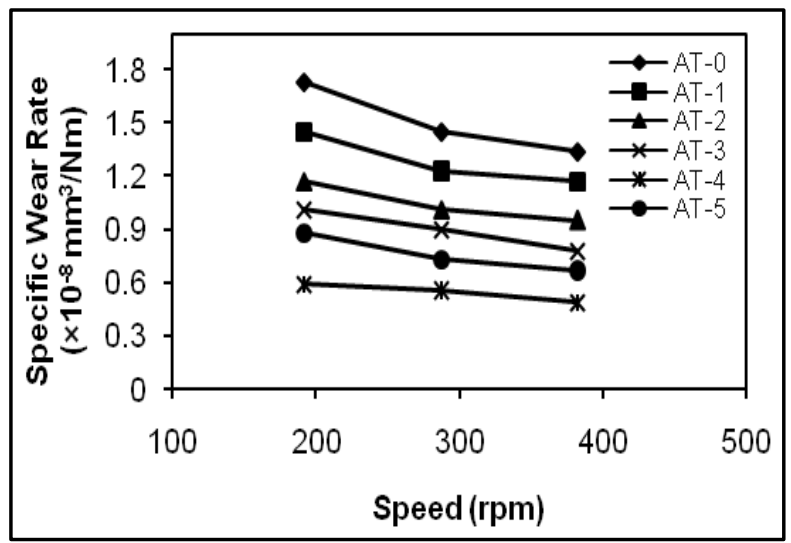

Fig6: Variation of specific wear rate with speed for aging time up to 5 hours $(\operatorname{Load}=10 \mathrm{~N})$

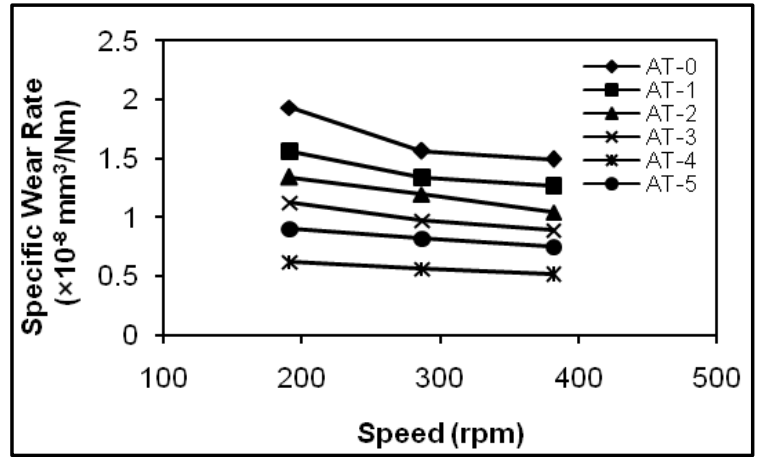

Fig7: Variation of specific wear rate with speed for aging time up to 5 hours $(\operatorname{Load}=15 \mathrm{~N})$

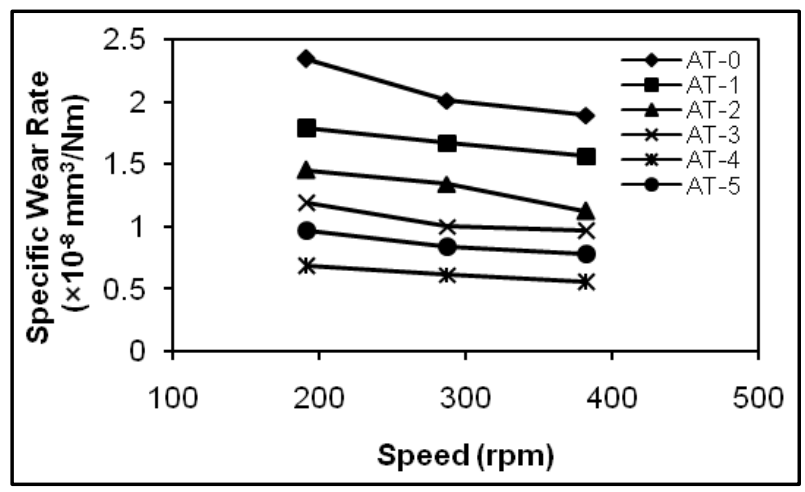

Fig8: Variation of specific wear rate with speed for aging time up to 5 hours $(\operatorname{Load}=20 \mathrm{~N})$

\subsection{Coefficient of Friction versus Hardness}

The coefficient of friction (COF) is a significant factor in understanding the tribological behavior. The plot of the COF with the hardness is shown in Figure 9 for the all the specimen loaded with $10 \mathrm{~N}$ at a speed of $191 \mathrm{rpm}$. It was found that the COF value marginally varied with the hardness of the alloy. The same result was obtained for other values of the load (15 N and $20 \mathrm{~N}$ ) and speed (287 rpm and $382 \mathrm{rpm})$. It is in agreement with the previous reports [3], [7] and [8]. Hence it can be concluded that the COF is independent of the hardness of the alloy.

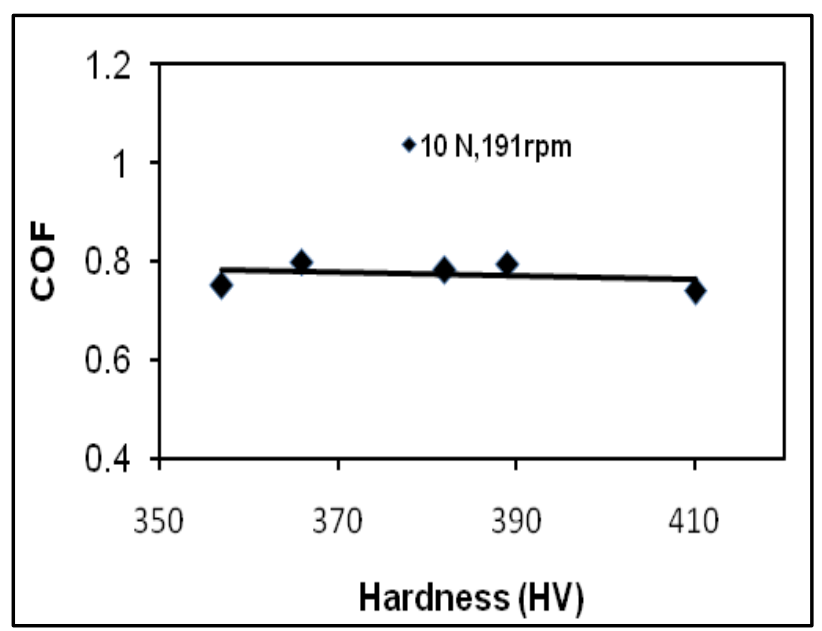

Fig9: Variation of COF with hardness of the alloy aged for different times 


\subsection{Coefficient of Friction versus Load}

A plot was drawn (Figure 10) between COF and the applied load of the specimen aged for 4 hours, run at $191 \mathrm{rpm}$ and having hardness value of $410 \mathrm{HV}$. It was seen that there was a decrease in the COF value. It may be due to the fact that the friction force increases with increase in load, however, it is not proportional to the increase in the load [14]. It was also reported that the increased surface roughening and a large quantity of wear debris were believed to be responsible for the decrease of friction with the increase of normal load [9]. This indicates that the COF is fairly dependent on normal load. Similar trend in the COF versus load was observed in other specimens also.

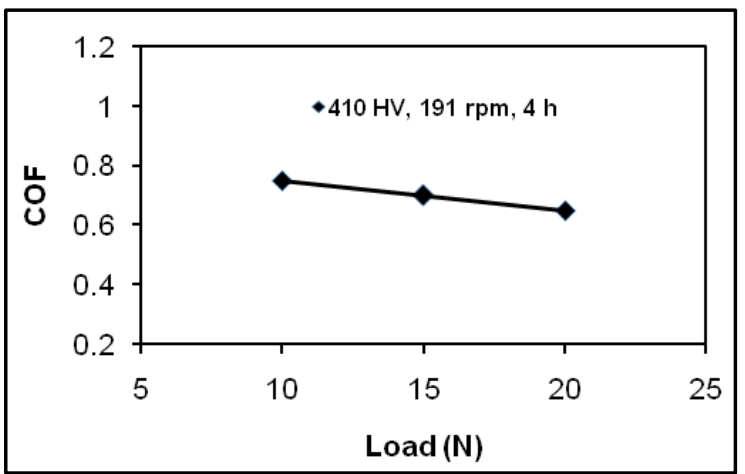

Fig10: Variation of COF with applied load of the alloy

\subsection{Coefficient of Friction versus Speed}

A plot was drawn (Figure 11) between COF and speed (in rpm) of the specimen aged for 4 hours, loaded at $10 \mathrm{~N}$ and having hardness value of $410 \mathrm{HV}$. It was found that there is a decrease in the COF with the increase of sliding speed. It may be due to the variation in the shear rate, which can influence the mechanical properties of the mating material [9]. The strength of this material was greater at higher shear strain rates, which resulted in a lower real area of contact and a lower COF in dry contact condition [9]. When the sliding velocity was increased, COF was reduced due to high interface temperature which might soften the specimen. This indicates that the COF is dependent on sliding speed. The same behaviour was observed in other specimens also.

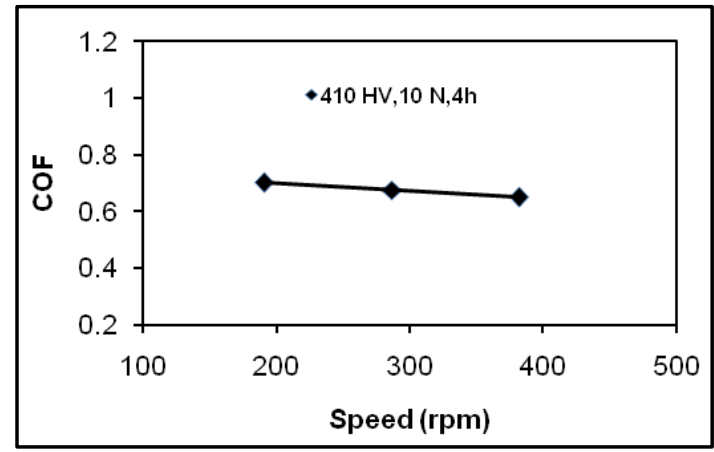

Fig11: Variation of COF with applied speed of the alloy

\section{CONCLUSIONS}

The following conclusions were drawn based on the results of this study of $\mathrm{Cu}-11 \mathrm{Ni}-6 \mathrm{Sn}$ alloy:

1 During the aging process, the hardness of the alloy increased from $238 \mathrm{HV}$ to $410 \mathrm{HV}$, which is due to microstructural changes (Spinodal decomposition and ordering reaction).

2 The specific wear rate increases when the normal load increases. But it may not be true for all loads. Initially, the specific wear rate increases up to certain loads and then remains constant. This behaviour is due to the strain hardening effect at the contact surface.

3 The specific wear rate decreases as the speed increases from $191 \mathrm{rpm}$ to $382 \mathrm{rpm}$. This is due to the fact that the duration of sliding (10 minutes) is same for all sliding speeds and hence the length of sliding is more in case of higher speed.

4 The specific wear rate is a function of hardness of the alloy.

5 Coefficient of friction was independent of the hardness of the alloy.

6 Coefficient of friction was dependent on both the applied load and speed.

\section{REFERENCES}

[1]. R Straffelini, G., Maines, L., Pellizzari, M. and Scardi, P. (2005), "Dry Sliding Wear of Cu-Be Alloy", Wear, Vol. 259 Issues 1-6, pp. 506-511.

[2]. Jeon, W.S., Shur, C.C., Kim, J.G., Han, S.Z. and Kim, Y.S. (2008), "Effect of $\mathrm{Cr}$ on the Corrosion Resistance of Cu-6Ni-4Sn Alloys", Journal of Alloys and Compounds, Vol. 455 Issues 1-2, pp. 358-363.

[3]. Zhang, S.Z., Jiang, B.H. and Ding, W.J. (2008), "Wear of Cu-15Ni-8Sn Spinodal Alloy", Wear, Vol. 264 Issues 34, pp. 199-203.

[4]. Baburaj, E.G., Kulkarni, U.D., Menon, E.S.K. and Krishnan, R. (1979), "Initial Stage of Decomposition in $\mathrm{Cu}$ 9Ni-6Sn", Journal of applied Crystallography, Vol. 12 Part 5, pp. 476-480.

[5]. Singh, J.B., Cai, W. and Bellon, P. (2007), "Dry Sliding of $\mathrm{Cu}-15 \mathrm{wt} \% \mathrm{Ni}-8 \mathrm{wt} \% \mathrm{Sn}$ bronze: Wear Behaviour and Microstructures", Wear, Vol. 263 Issues 1-6, pp. 830-841.

[6]. Zhao, J.-C. and Notis, M.R. (1998), "Spinodal Decomposition, Ordering Transformation, and Discontinuous Precipitation in a Cu-15Ni-8Sn Alloy", Acta Materialia, Vol. 46 Issue 12, pp. 4203-4218.

[7]. Ilangovan, S. and Sellamuthu, R. (2012), "An Investigation of the effect of $\mathrm{Ni}$ Content and Hardness on the Wear Behaviour of Sand Cast Cu-Ni-Sn Alloys", International Journal of Microstructure and Materials Properties, Vol. 7 No. 4, pp. 316-328.

[8]. Ilangovan, S. and Sellamuthu, R. (2013), "Effects of Tin on Hardness, Wear Rate and Coefficient of Friction of Cast Cu-Ni-Sn Alloys", Journal of Engineering Science \& Technology, Vol. 8 No. 1, pp. 34-43.

[9]. Chowdhury, M.A., Khalil, M.K., Nuruzzaman, D.M. and Rahaman, M.L. (2011), "The Effect of Sliding Speed and Normal Load on Friction and Wear Property of 
Aluminum", International Journal of Mechanical \& Mechatronics Engineering IJMME-IJENS, Vol. 11 No. 01, pp. 45-49.

[10]. Taltavull, C., Torres, B., Lopez, A.J. and Rams, J. (2013), "Dry sliding wear behavior of AM60B magnesium alloy”, Wear, Vol. 301 Issues 1-2, pp. 615-625.

[11]. Chowdhury, Mohammad Asaduzzaman and Helali, Md. Maksud (2008), "The effect of amplitude of vibration on the coefficient of friction for different materials", Tribology International, Vol. 41 Issue 4, pp. 307-314.

[12]. An, J., Li, R.G., Lu, Y., Chen, C.M., Xu, Y., Chen, X. and Wang, L.M., (2008), "Dry sliding wear behavior of magnesium alloys", Wear, Vol. 265 Issues 1-2, pp. 97-104.

[13]. Zhang, Y.S., Han, Z., Wang, K. and Lu, K. (2006), "Friction and wear behaviors of nanocrystalline surface layer of pure copper", Wear, Vol. 260 Issues 9-10, pp. 942948.

[14]. Sudarshan and Surappa, M.K. (2008), "Dry sliding wear of fly ash particle reinforced A356 Al composites", Wear, Vol.265 Issues 3-4, pp. 349-360.

\section{BIOGRAPHIES}

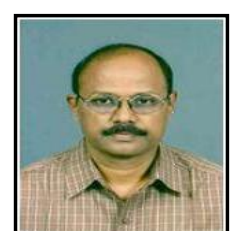

Dr. S. Ilangovan has completed his Bachelor's Degree in Mechanical Engineering and Master's Degree in Production Engineering. He has fourteen years of experience in industry and sixteen years in teaching. He has also completed

Ph.D. in Materials Engineering

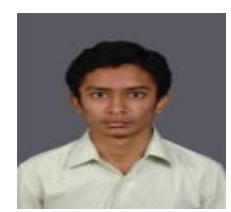

S. Jiten has completed his Bachelor's degree in Mechanical Engineering and currently pursuing his Master's degree in Manufacturing Engineering at Amrita Vishwa Vidyapeetham, Tamil Nadu 